\title{
Entre la religión y la filosofía: La polémica de Isaac Orobio y Alonso de Zepeda*
}

Fernando Díaz Esteban

In memoriam Antonio Peral Torres

\section{CONTRARRÉPLICA}

El ataque de Orobio a Lulio y a Zepeda lo publica Zepeda antes de su contrarréplica por las razones que él mismo declara y hay que agradecérselo. Se ve también que Zepeda todavía tiene una tenue esperanza de que Lorenzo Escudero vuelva a la religión católica, de la que procedía, y esta esperanza es uno de los ingredientes de su contrarréplica.

Zepeda se justifica:

Y por medio del Excellentissimo Señor Don Estevan de Gamarra, Embajador de su Majestad à las Provincias Vnidas, procuré se entregase en mano propia de la tal persona. Y reconociendo que executada esta diligencia se ha pasado dos años sin que me hayan respondido, y que pueden ocultando mi respuesta divulgar entre los de su gremio, que los Católicos no havemos podido respoder à sus errores, ny yo defender la doctrina de Raymundo Lulio. Y que todo esto podia redundar en oprobio de nuestra Religión, y en menoscabo de la verdad de tan soberano misterio, originando mayor fomento à su pertinacia judaica: solicitado así mismo de mi conciencia, y de algunas personas doctas, que desean tener esta controversia, he resuelto darla a la estampa en dos lenguas, para que se divulgue tambien entre aquellos que no saben la Española. Nota ahora si asisten à mi

* Continuación de Sefarad 61(2001) págs. 319-344.

Sefarad 62 (2002) págs. 21-55

(c) CSIC

ISSN 037-0894 
osadia bastantes excusas, y si las tuviera el ocultar al mundo lo que puede ser publique la Sinagoga en su abono, encumbriendo mi defensa para dar mayor fuerça à su contumacia, y desdoro a la Iglesia nuestra Madre Sactissima? ... No buscando las frazes elegantes ni en una ni en otra lengua sino sola la substancia: Porque ademas de ser dogmatica la materia, en la Española no las affecto: y menos en la Latina, cuyo exercicio me embarazaron, ha muchos años, las ocupaciones militares ... para la total inteligencia de algunas cosas deste discurso, sera necesario acudas al Arbol de las Ciencias que te he referido. Vale.

Sigue la Réplica de Orobio ya vista y luego la Contrarréplica.

\subsection{Respuesta de Alonso de Zepeda}

La contrarréplica de Zepeda ocupa las páginas 79 a 299 y también se presenta como una carta escrita a Lorenzo Escudero. Tras el título Respuesta De D. Alonzo De Zepeda A las cartas y questiones susodichas, que le remitiò el dicho Lorenço Escudero y otros de la Synagoga, à quienes la remitiò el Autor, viene el texto de la carta. Es de advertir la mutua cortesía en el tratamiento de los polemistas, aunque se acusen de ignorantes o malintencionados.

Señor mio: Reciby una carta de Vuestra M. de 13. de el passado, y cierto papel en respuesta, no de el libro de Raymundo Lulio, my Maestro iluminado; sino solamente de dos questiones. Para cuya obgeccion no se necessitaba de tiempo tan dilatado; por que son las mas ventiladas en la ley, que vuestra M. sigue por su desdicha. Pero mas vale tarde que nunca: pues asi me ha sacado de la impaciencia, en que me tenia su silencio, quando me asiguro hyperbolicas promptitudes en la opugnacion del libro Luliano. Aunque si lo pondero con cuydado, debo reconocer que vuestra M. a pesar del tiempo ha cumplido con su palabra, porque para semejantes proposiciones, no se requieren muchos dias ny continuados desvelos; basta un solo momento. Pues son un aborto de ignoricos oprobios, y de mal limados argumentos: sin que arguya energia ny vigor en ellos la presumpcion que ostenta esse cavallero, haciendo alarde de que lo entiende todo, exagerando sus dificultades por indisolubles, y aprobando por infructuosos los fertilissimos arboles de Raymundo Lullio. De los quales (con licencia suya, y de vuestra M. Señor Lorenço) no ha penetrado, ny una hoja sola: no obstante que en el modo de proponer descubre ser Philosopho y versado en la doctrina de las escuelas Catholicas: pero en la de Raymundo Lulio, creame 
vuestra M. que no entiende palabra: y es menester que estudie de nuevo, si quiere tener luz de las verdades, que produce este fecundissimo Arbol de todas las Ciencias, para mayor bien suyo. Y por que vuestra $M$. se desengañe, y el mismo (si tiene razon) lo reconosca, Responderè punto por punto à el papelejo (aunque su estilo no lo merecia) esperando que my discurso excitara à que vuestra M. abra los ojos, y esse cavallero, que en el suyo supone no ser su intento impugnar religion alguna, quando sus obras y escritos dicen lo contrario. Pero no obstante, como la mia me enseña à ser mas caritativo, seguirè sus preceptos, declarando lo que alcanço de el mas alto de sus sacrosantos mysterios. Aunque con todo recelo de que se dira por my trabajo quod Aetiopem lavat: porque como vuestra M. sabe muy bien, el refransillo Castellano: Jamas de Rabo de \& Me asegura de que sera frustraneo my cansancio; pues procedo contra lo que me amonesta S. Matheo, diciendome Nolite dare semetum canibus, \&c. Porque vuestra voz sera como la de el Bautista.

Como había hecho Orobio, su trabajo consta de dos partes. En la primera, articulada con letras, hace consideraciones generales; en la segunda, responde uno a uno a los 25 puntos de Orobio.

\subsubsection{Primera Parte (págs. 85-162)}

AB. Passando pues à la respuesta de todos los periodos ò capitulos de el papel, digo à el. Que me admiro, y con razon no poca, de que siendo esse Cavallero (que llamare de aqui adelante el Respondiente) segun obstenta Phisico y Metaphisico, que menosprecie tanto los terminos abstractos: pues no ignora, que mientras mayores abstracciones hiciere nuestro entendimiento en qualquier ser, se acercara mucho mas à el conocimiento de su essencia; y mientras mas precissamente de el arte Analitica, tendra mayores noticias de sus propiedades y essencias. Y por esta causa aquella ciencia se tiene por mas perfecta, que da claridades mas verdaderas y particulares de su abgeto. Siendo esto assy, como el Rep. opugna ignominiosamente los terminos abstractos de Raymundo Lulio, pues por ellos puede ascender nuestro entendiemiento à el ultimo conocimiento de una cosa: como el ente, en quien debemos considerar el Reubau $^{2}$ que se le atribuye. Esto es, que sea cosa, uno, bueno, verdadero y distincto de otro (esta explicacion es para vuestra M. Señor Lorenço no para el Señor Resp. por que no dudo que la entiende; pero no los abstractos de Raymundo Lulio) sino tambien la quiddidad de el mismo ente, y aquellas, de que la de este està compuesta, para poder conseguir la noticia, que debemos tener de el, como que el ente supone el ser, y este

${ }^{2}$ Las palabras latinas res, una, bona, veritas. 
la essencia: por quanto el ser es por razon de la essencia, no essencia por razon de el ser. que esta essencia tiene naturaleza; porque de otra suerte seria ficticia. Que esta naturaleza tiene su quiddidad, ò seria nada. Y consiguientemente todo lo que palpamos y vemos no seria ente real: luego impropiamente reprueba el Resp. los abstractos de Raymundo Lulio, pues por ellos venimos à el conocimiento de la mas real y asendrada Metaphisica y de la Philosophia verdadera: no ocasionando las tenebrosidades que dice esse Cavallero, sino por lo contrario clarissimos fulgores ... meditando el alto y sublime methodo, que tiene en manifestar todas las ciencias, y su profundissima doctrina. En que se conoce manifiestamente haver sido iluminado de Dios ...

Y no son señales de un maduro juycio, atribuir à deffecto de la ciencia, y de el maestro, el que no sea entendido de qualquiera; porque con esto quedarian abatidos y tenidos por ignorantes Hermes, Socrates, Platon, y Aristoteles Principes de la Phylosophia, por quanto son obscuros, enigmaticos, y hasta ahora entendidos de pocos, aunque bien adulterados de muchos. Y por esto, si el Resp. no ha comprehendido el Arbol de la Ciencia, ò si lo ha leydo (como dice que ha escrito) currente calamo, no tengo yo la culpa, Señor Lorenço, de su ignorancia, ny menos Raymundo Lullio de que tenga por obscuro y poco fructuoso; quegese [quéjese] esse Cavallero de su poca contemplacion y poca vista; pues à sus luces se quedo en tinieblas, que lo mismo haze un ciego à los rayos de el Sol, que aunque le calienta y vivifica no conoce la perspecuidad de su cuerpo luminoso.

C. Mal deduce el Resp. de su poca inteligencia, confusa affectacion, ò ambiguedad en las frases de Raymundo Lullio, puès huyendo este admirable Doctor de semejante deffecto, usò siempre en sus libros de un Latin poco pulido, (excepto en la Rhetorica, y en la oracion que pone por ejemplo) para ser entendido de todos con mayor facilidad y ser conocido con su estilo por auctor de los muchos libros que compuso. Y esto mismo adverti yo en el Prologo de el libro; para que el estudioso no atendiesse tanto à sus frases y eloquencia, sino à la substancia de su doctrina, que es la que deben inquerir los hombres assy sabios, como doctos; esto para salir de su ignorancia, y aquellos para subtilizar mas, no las voces de las cosas, si su naturaleza. Y es supuesto y fingido, que el estilo de Raymundo Lullio sea lo que dice el Doctor Angelico en materia Theologica; porque antes tuvo el mismo, deduciendo terminos, y las voces mas representativas de las cosas. Como se reconoce por las cien formas [en el Ars Magna], por los abstractos y concretos de sus principios, y por otros terminos que no pueden exprimirse [expresarse], sino por voces inventadas de nuevo, que se deben tener por dogmaticas, de que usan tambien, y han usado muchos Theologos. Y cierto que es reparo muy nominal el que se termina solo en las voces, haviendo tanta substancia en su significado.

D. ... es necessario, para los unos [principiantes] començar desde los primeros elementos, y para los otros [peritos] deducir con conclusiones 
assentadas, y las difiniciones, divisiones y subdivisiones convenientes, para que conoscan las essencias y naturalezas de las cosas, de que trata. Como haçe Raymundo Lullio en el Arbol elemental, y en los demas. Por que de otra suerte todas las ciencias serian confusiones y no se tendria en ellas fin ny principio. Es muy forçoso proceder por sus grados; y desde el primero, que son los elementos, ascender hasta el ultimo ... no por esso el Resp. siendo tan estudioso, debe tener por desaçonados sus arboles, ni por infructuosos sus rayces: porque no lo son, sino solo para quien no puede, ò no quiere penetrarlos; cuya costumbre es jusgar por deffectuso e inutil todo lo que sobrepuja su entendimiendo.

E. ... pues tomando este eminentissimo Maestro solo siete cosas (que se hallan en qualquier arbol) por lugares comunes, hace que sirvan a la memoria ... Y cada Ciencia la reduce à siete capitulos, ò clases ... excusando assy la inmensidad de preceptos, reglas, terminos y proposiciones, de que usan ordinariamente en las escuelas ... De que se infiere que el Resp. miro el arbol Luliano con antojos [anteojos], que multiplican los obgetos, ò que se le passò por alto su inteligencia, pues afirma ser Griego todo para el que lo lee ... Porque si Raymundo Lullio no trata expressamente de el ente ut sic en esta obra, es ò porque lo explicò en su oydo cabalistico ... ò que hablando de el ente summo y participado lo incluya [incluía] todo. Y si el Resp. huviera leydo my introductorio, no se arrojara à decir semejante testimonio, porque en el se hablò bien dilatadamente de el ente verbal; y se tratò, aunque con brevedad, de todas las ciencias ... inferiores a la Theologia ... Y si no me dilate en la Logica, fue porque la tengo comentada en particular, y espero sacarla muy presto à $\operatorname{luz}^{3} \ldots$

F. Y ciertamente que es osadia temeraria la de el Resp. quando se precipita à baldonar de sophismas los argumentos concluyentes de Raymundo Lullio ... pues no discierne los silogismos de los parasilogismos ... que enseña qualquier Dialectica ... Y no contento con manifestar su rencor contra tan altas verdades, buelve las armas de su ignorancia contra la traduccion juzgandola por mal Castellano para el latino y por buen Latin para los Castellanos, ò para los legos ... Pero si el no entiende al arbol, $[i] q u e$ culpa tengo yo, Señor Lorenço? y menos en que, siendo estudiante, siga la opinion comun de los estupidos, de que no puede haver Ciencias, ny explicarse, sino en la lengua Latina ... Pero es notorio que los Egipcios tubieron las Ciencias de las Caldeos, y los Griegos de ellos, y de estos los Latinos, poniendolos cada uno en su lengua materna. Y oy hazen lo mismo todas las naciones de Europa, y creo que podemos los Españoles goçar de el mismo privilegio ${ }^{4}$.

\footnotetext{
${ }^{3}$ No tengo noticia de que finalmente Zepeda publicase un tratado de Lógica.

${ }^{4}$ Es la razón que da en la «Dedicatoria» de su traducción del Árbol de la Ciencia de Lulio.
} 
G. ... juzga por nuevo à Raymundo Lullio ... y my trabajo por superfluo ... Lea otra vez, le suplico, todos los autores que yo cite en su vida ... los privilegios ... los pleytos, que los emulos ... fomentaron contra su doctrina ... Lea a Munstero [Musnter] en su Cosmographia à fol. 72. y 74. $\mathrm{y}$ alli verà como pone à Raymundo Lullio entre los hombres ilustres de España por su admirable Ciencia ...

Pero temo que todo le parecerà Griego ... no quiere desvelarse en lo que no desea saber. Y por esso arguye ... por inutil el quitar el polvo à los Philosophos antiguos, que fueron la basis de todas las Ciencias. En las quales todos los autores que cita hicieron varios progressos cada uno por su camino y particular dictamen ...

Lullio tuvo por dictamen particular el philosophar segun las obras de la naturaleza, para deducir de ellas raçones naturales, mediante las quales pudiesse explicar y dar à conocer à los Judios y Mahometanos las producciones divinas: ya que no puede convencerles, el ser establecidas por la Yglesia, ny el ser reveladas por Dios. Y este es el bien, que siempre pidiò este Varon justo ...

... me obliga antes de passar à la solucion de sus obgeciones ... probar de nuebo ... deben darse de necessidad necessitante semejantes abstractos y concretos, ò correlatos en todos los seres y essencias de las cosas ...

Esta doctrina de los concretos y correlatos intrinsecos de Raymundo Lullio, es la misma que enseña Aristoteles (aunque lo entienden pocos) porque en en lib. I de el cielo y de el mundo [De coelo et mundo] con otros muchos philosophos dice: quodlibet ens perfectum habet potentiam agendi \& patiendi Qualquier ente perfecto tiene potencia de obrar y de padecer ... ò no sera ente, ni essencia perfecta en raçon de ente ... no tendría naturaleza ... y si la tiene sera ociosa y vacua de fin ... Aristoteles ... en el lugar cit.: Tria sunt in qualibet re, videlicet natura, virtus, \& operatio Tres cosas hay en cualquier cosa, es à saber naturaleza, virtud y operacion ... luego en cualquier essencia v. g. [verbi gratia] en la bondad hay las tres cosas referidas, las quales explica Raymundo Lullio por el tivo, bile y are; que son el Bonificativo, Bonificable y Bonificar ... Por lo qual influyendo el Bonificativo en el Bonificable mediante el Bonificar, resulta la Bondad ... Todo lo qual explique en mi introductorio, quando trate de los predicamentos y en otros lugares. Pero sino los ha entendido esse Cavallero, [i]que culpa le tengo yo, Señor Lorenço? [i]Ni de que aborresca tanto las abstraciones Metaphisicas? ... Pero debe ... confesar, que no conoce, sino solamente los concretos y abstractos que en las escuelas llaman totales, como la Bondad y lo Bueno. Pero seria coartar mucho su entendimiento, quando se jusga superior à el de todos, y aun àl de el mismo Raymundo Lullio, segun se chancea con sus hojas. ... [Considerando] el ser, su semejança, el no ser, y su semejança ... Quedan solo el ser, y su semejança en todo lo increado y lo creado; ahora pues el ser es Dios: luego su semejança es todo lo creado ... no se puede hallar perfeccion en lo creado, que es la semejança, que no se halle mas perfectamen- 
te, en lo semejante, que es Dios ... es perfeccion grande la fecundidad y generacion, è imperfeccion la esterilidad ... en Dios debemos ... y atribuirle lo que es perfecto. $\mathrm{V}$ [o] de otro modo sera imperfecto y menos que las creaturas.

Que se da en Dios esta perfeccion de fecundidad lo dice el mismo en diversos lugares de las Sagradas Letras. Primeramente Abraham en el Genesis cap. 18 ... quando vio a tres Angeles y adoro solo a uno ... dixit: Domine si inveni ... Señor si halle. Jacob ... tantas veces como Dios se le aparecio y el levantò altar para sacrificarle, solas tres veces la llama casa de Dios Gen. 28 y 35 ... En la bendicion que mando al Sumo Sacerdote Aron echase à su pueblo ... Benedicat tibi Dominus ...ostendat Dominus faciem tuam tibi ...convertat Dominus vultum suum ad te ... Tres veces dice El Señor y no mas significando la produccion de las tres divinas Personas ... [y las doce tribus y las doce piedras del pectoral] si esse Cavallero es Philosopho fundado en lo arcano de la naturaleza, sume esse numero [12], y hallara tres, representando assy las tres personas en una essencia ...

Y que hay esta fecundidad en Dios lo canta bien claramente el Rey Propheta en el Psal.2. Filius meus es tu, ego hodie genui te ... querer interpretar ... diciendo se ha de entender de David, es desvanecer; porque el no diria de sy mismo, que era Hijo de Dios. Y contradiciria à Mich. 5. ex te mihi egredietur qui sit Dominator in Israël, \& egressus eius ab initio à diebus aeternitatis ... Y esta divina produccion de el Hijo la volvio a repetir David Psal. 109 Dixit Dominus Domino meo sede à dextris meis \&. Dijo el Señor a mi Señor sientate a mi diestra. Sin que sea de consequencia la solucion, que da V. M. Señor Lorenço, con todo el Judaismo à este texto, queriendo lo haya compuesto un criado de un criado de David, y que lo dijo por el. Lo que seria groseria ... que el criado se sentase a la diestra de su Rey. Pero ... el distico siguiente Ex utero ante luciferum ganui te. Engendrete antes que à el Lucero. Pero ya se que se hallo remedio à esta dificultad, quitando este verso y adulterando la Escritura. Pero quiso Dios que dejasen el siguiente Juravit Dominus \& non poenitebit eum. Tu es Sacerdos in aeternum secundum ordinem Melchisedech Lo qual no pudo convenir a David ... solo al Hijo de Dios.

Cuya generacion y fecundidad la significa Salomon proverb. 8 ... Ante omnes colles ego parturiebam. Yo paria dice el Señor. Esto es[,] yo cree antes que fuessen creados los collados y montes. Lo que confirma Isaias cap. 66 ... Numquid ego, qui alios parare [parire] facio, ipse non pariam? Dicit Dominus exercituum: si ego qui caeteris generationem tribuo, sterilis ero? Por ventura yo que hago parir los otros, $[i]$ no parire yo mismo? Yo que doy generacion à los otros, $[i]$ sere esteril? $[i]$ Quierelo V. M. mas claro Señor Lorenço? diga V. M à esse Cavallero que responda à todos estos textos, que bien se no puede ... 
Que se halle en todas las cosas el triuno, se ha probado en mi introductorio [al Árbol de la Ciencia] ... y al Señor Respondiente [remito] à los libros de Trismegisto en su Pimandro y à Mopolito, Bacon, Conde Tramesan, Conrado y otros excelentes Philosophos Hermeticos ... En todos ellos vera como cualquier elemento se reduce à los tres principios, àzofre, Sal y Mercurio; y en su mayor simplicidad a los tivos biles y ares de Raymundo Lullio. [El triuno se encuentra en todas las cosas por la semejanza con Dios] Pero con una distincion, que en lo semejado hay una essencia indivisible, y tres supuestos realemnte distinctos. Pero en la semejança, ò son tres cosas ... de una essencia; ... ò son tres cosas de diferentes essencias.

Dios no seria Dios ... pues se daria en el la minoridad de la esterilidad siendo infecundo de si mismo ... luego Dios produce desde toda su eternidad lo infinito, que es el mismo Dios ... y se dan en el el produciente y lo producido ... todo lo que Dios produce ad intra es substancia y persona: luego en Dios se da la pluralidad de personas ... [el Hijo y el Padre y su amor es] actual, reciproco, perfectissimo, infinito y eterno ... luego en Dios se da el amante: y el amado, y el amor ... [que es] el Espiritu Santo y tambien Persona ... luego en Dios se dan las tres personas ...

Por el triuno ... en los entes creados ... es necesario se den el bonificativo, bonificable y bonificar, grandificativo, grandificable y grandificar, el unificativo, unificable y unificar, \&c. En lo creado ... sin que el uno sea el otro. En lo increado cada uno es essencialmente el otro, y se identifican todos en la essencia y naturaleza divina ...

Estos son los correlativos de Raymundo Lullio que tanto repugna al Resp. Y esto sin duda Señor Lorenço, porque no los entiende; no obstante que es gran Philosopho, y no poco versado en la Theologia Chirstiana ...

Con que dejando mayores disgresiones, como pedia esta materia, passo à la solucion de las obgeciones, para que vea V. M. que no son insisolubles, como lo presume esse Cavallero.

\subsubsection{Segunda Parte (págs. 163-283)}

Zepeda va refutando en su mismo orden los puntos numerados que había expuesto Orobio en su Respuesta. A esta Segunda Parte Orobio no contestará en su segunda réplica, porque se limitará a atacar las interpretaciones de los versículos bíblicos que había presentado Zepeda en el apartado G de la Primera.

Zepeda se queja de que Orobio se quede en la crítica a la terminología abstracta y en las supuestas dificultades de lectura del Árbol de la Ciencia, sin tener en cuenta que Lulio sólo buscó los términos más naturales «para probar este divino misterio contra 
los Judios y Mahometanos»; la consideración de Iluminado está en los documentos «que si huviera leydo el Respondiente, no propusiera obgeciones, que estan manifestando su poco cuydado, ò corta inteligencia» (puntos 1 y 2).

Sobre la cantidad (punto 3) Lulio y todos los católicos «respondemos que no hay en Dios nec molis, nec virtutis, nec operationis; porque es infinito ... quantidad discreta ... no se da sino entre cosas que son ... de diversas essencias y supuestos ... pero en Dios ... no constituye diversas unidades, sino una unidad». Orobio ha tomado la Trinidad substantivamente,

pero tomandola adjetivamente se puede decir que hay tres unidades ... son una misma essencia y naturaleza (segun confiesa el mismo Respondiente) aunque distinctas realmente entre sy, sin que por esso sean tres unidades tomadas substantivamente, ni tres en numero predicamental: porque para esto se requiere la distincion de essencias ... por ser de una misma essencia, no constituien absoluto ny predicamental ...

Quando Raymundo Lullio niega unidades en Dios, se ha de entender en substantivo, y quando las concede, en adjetivo: como haçen todos los demas Theologos ... estas hojas del Arbol Luliano vea Vuestra Merced ahora, Señor Lorenço, si havemos hallado entre ellas la respuesta, que dudaba este Cavallero, y el fruto, à cuya investigacion nos remitio; y que el buscò sin poderle topar. De que no me espanto: porque su Ley le tiene muy atenuada la vista, y el entendimiento pleno de tenebrosidades.

Zepeda defiende a Lulio, al que Orobio (punto 4) no ha leído bien, pues no ha dicho que la bondad y demás razones no sean la misma esencia de Dios «Y cada una es qual por la generacion y espiracion, en la qual hay distinccion de Personas. No puede declararlo mas Raymundo Lullio, ni explicarlo mas catholicamente».

Sobre los usos escolásticos (punto 5)

respondo, que este Eminente Maestro no quiso usar de los terminos, ni de las comparaciones, que hazen en las Escuelas, porque son buenas para los versados en ellas; sino solo de los terminos y exemplos naturales, para que los ignorantes en las ciencias las entiendan. $\mathrm{Y}$ ansi dice que Dios es uno en dos modos, uno segun la substancia, como Martin es una substancia ... esto es un individuo indiviso en si, y diviso de qualquier otro ... Lo qual dice en raçon substantive. No de composicion ... Y no hay indecencia de hablar de lo semejado ... siendo el intento de Raymundo Lullio usar de terminos y exemplos que lo entiendan todos ... analogica- 
mente respecto de Dios; y no por esso deja de ser [Dios] ente perfecto y substancia perfecta.

Viene luego la discusión sobre la naturaleza seca del fuego, que Orobio dice que lo es por la tierra:

me admiro ... diga semejante desproposito ... pues Aristoteles y Hermeticos y la mayor parte de los demas Phylosophos dan quatro elementos y a cada uno su qualidad propia, y su qualidad apropiada. Y assi la sequedad es propia de la tierra, y apropiada al fuego ... porque la cosa propia, lo es de tal manera de cada uno, que no puede ser de otro.

Sobre la pluralidad (punto 6) Zepeda responde que

lo mismo es decir de la pluralidad de Dios, que de la pluralidad en Dios ... porque haviendo probado Raymundo Lulio con raçones naturales y evidentes, no haver mas que un Dios: hablando luego de la pluralidad de Dios se entiende solo de las personas en su divina essencia. Porque a ser los idolos y deidades que se finge el Resp. dijera de la pluralidad de Dioses en numero plural ... De todo lo qual se reconoce quan atropelladamente quiere el Respondiente obscurecer la doctrina de un Doctor tan eminente ...

Reprocha a Orobio (punto 7) el tono de su réplica, porque

jamas he visto, que los hombres, que quieren ser estimados por los doctos, respondan con escarnio y fisga à los puntos relevantes de las Ciencias ... le energia de las Ciencias consiste en la substancia, no en la elegancia de los terminos; y que estos son buenos siempre que explicaren bien la essencia de la cosa ... Porque concediendo que en Dios (como confiesa el Christiano, el Judio, y el Moro) hay bondad, infinidad, eternidad, omnipotencia ... en todas ellas se dan sus correlatos intrinsicos, que son la misma essencia del abstracto, y de el mismo Dios, y desde toda la eternidad estan obrando, esto es, engendrando el verbo por el entender y espirando el Espiritu Sancto por el amar ... libres de la ociosidad y del vacuo ... el bonificativo, bonificable y bonificar ... no son tan juguete, como se los sueña el Resp. porque no los entiende. Son pues raçones ... para probar las producciones ad intra de la essencia divina ... Como yo procurè explicar en el introductorio del libro. En que se conoce que no lo ha leydo esse Cavallero, ò no lo ha entendido.

Orobio se equivoca (punto 8), pues

ningun Catholico hay (y menos Raymundo Lullio) que diga que en Dios hay voluntad, entendimiento, unidad, sabiduria \&c. fuera 
de su ser; porque ... se identifican en la essencia divina y son el mismo Dios. Y todo lo que se halla en las creaturas, se lo ha comunicado Dios por analogia de proporcion.

El entender, la voluntad, el querer y el ser de Dios son una misma cosa si se habla de ellos esencialmente; pero no si se habla nocionalmente «por quanto entonces conotan las propiedades [características respectivas], y se distinguen realmente por ellas», para lo cual basta con «que sean opuestos relativamente». Orobio no ha leído bien, cuando dice que en Lulio la bondad, infinidad, unidad de Dios son formas bonificativa, infinitiva y unificativa de Dios,

Quando por lo contrario en todo el Arbol Apostolical, y en el Divinal prueba, que todas estas raçones (que llama formas para poder explicarse) y cada una de ellas son el mismo Dios, y cada una la otra; pero que siendo Dios bueno y la bondad misma; y siendo esto en lo creado la raçon de que lo bueno produsga lo bueno; es necesario que lo sea en Dios con mayor perfeccion desde toda la eternidad ...

por lo que ha obrado en su Hijo.

Son ociosos los ejemplos que da Orobio (punto 9), porque Lulio no dice lo que le atribuye. Zepeda niega (punto 10)

el supuesto, de que estas raçones o formas, sean fingidas ... porque su existencia no depende de nuestro entendimiento ... Danse pues en Dios estas raçones essencial y realmente ... no denominativas sino activas y productivas como el mismo Dios ... para que desde toda su eternidad estè ... produciendo para siempre a su Hijo ... repetirè ... como las definiciones son quid rei ò quid nominis, y que por estas se pueden difinir todas las voces y dicciones ... quid rei es la quidditiva, ò la que explica las essencias ... luego la bondad y demas razones, para ser constituidas en sus essencias ... es necesario tengan sus correlativos, que son (como se ha repetido tan reiteradas vezes) el bonificativo, bonificable, bonificar, \&c.

Zepeda insiste en que las «razones» son activas y el mismo Dios, en la distinción entre origen y tiempo, y se lamenta (punto 11):

no puedo dejar de reprobar el estilo, que tiene el Respondiente en opugnar la doctrina de Raymundo Lullio ... Pues no teniendo razones para responder ni para contradecir à las de Lullio, se arroja à decir, que su modo de discurrir es contra el sinderesis de la razon ...

La bondad, eternidad ... \& c. no informan a Dios como subgetos; pues ellas son el mismo Dios, y son raçones realces en Dios 
... por quanto Dios bonifica por la bondad, y no por la grandeza ... no porque no sean una misma cosa; sí, porque ... à cada una le compete su acto ... es necessario que sean activas, y productivas, ò serian mera potencia, y entonces se daria en Dios composicion ... Tampoco ha dicho Raymundo Lullio que estas raçones sean principios de Dios, porque su ser no tiene principio ni fin, pero son el mismo Dios y en el son son principios de las producciones divinas. Por quanto el Padre es principio principiante, y no principiado, y el Espiritu Sancto es principio principiado y no principiante ... [por] prioridad de origen, no de tiempo ni de naturaleza. ... enseña la Philosophia, diciendo, que los predicamentos son principios, y no efficientes (como se probò en el cit. introductorio fol. 23) y pudiera haverlo leydo esse Cavallero antes de ally se declarò tambien, como Raymundo Lullio llama estas raçones principios ... Y assy mismo que en Dios concedian todos los Theologos el principio quod y quo, donde no hay effecto ni causa.

En las cosas creadas están las semejanzas (punto 12) con Dios,

$\mathrm{Y}$ assy son frustaneos los exemplillos de lo calido y de la blancura, y ademas aplicados falsamente. Porque si la blancura no tubiera actividad ni operacion intrinsica, no pudiera dar su semejança ... tiene sus correlativos de su essencia, que son blanqueativo, blanquable y blanquear, y lo mismo en el calor.

Se repite (punto 13) una queja habitual en Zepeda:

el Resp. aunque es muy gran Philosopho, no ha entendido una palabra sola de todo el Arbol Lulliano. Porque [i]quien es el que ha dicho, ò dice ... que Dios es eterno por la eternidad \&c.[?] notelo por vida suya, y V. M. me lo remita Señor Lorenço. Por quanto Raymundo Lullio solo dice que la eternidad, bondad, unidad \&c son raçones en Dios, y que son el mismo Dios. Por lo qual Dios no es eterno por la eternidad, ni bueno por la bondad \&c. sino la eternidad, bondad y la mismo unidad. Pero como la Bondad es raçon de que lo bueno produsga [produzca] lo bueno, y la eternidad produsga lo eterno, y la unidad de que produsga lo uno, es necessario que Dios produsga lo bueno, uno y eterno, que es su hijo. $\mathrm{O}$ se seguirà que Dios y todas sus raçones son mas imperfectas que todas las cosas creadas; sin que estas seguras razones sean ficciones del entendimiento humano. Porque de otra manera ... sera justici[e]ro y misericordioso solo porque lo fingimos: conque tendriamos un Dios chimera [quimera] ... el que se propone el Resp. De lo que no me espanto, pues apartado de la gracia, no puede discernir cosas tan altas ni distinguir lo real de lo chimerico, ni lo verdadero de lo falso. 
Se opone Zepeda a la afirmación (punto 14) de que las «razones formales» solamente sirvan para denominar a Dios, sin que tengan actividad, porque

estas raçones formales son el mismo Dios, y que no le denominan, sino es metaphoricamente ... Ni se dan en Dios denominaciones ad intra, pero bien ad extra. $\mathrm{Y}$ assy como Dios es acto puro, y productivo, lo son tambien sus raçones ... no que Dios, ò sus raçones, adquieran alguna perfeccion por el obrar ... sino que la perfeccion, essencia y naturaleza de estas razones consiste en el obrar, porque de otra manera serian ociosas.

Orobio había planteado la cuestión de hasta qué punto los atributos o «razones» son meras elucubraciones de nuestra mente para poder figurarnos a Dios. Zepeda en su contestación (punto 15) exhibe sus conocimientos de la técnica de la disputa escolástica con el «concedo», el «nego», el «distingo» y el empleo de su terminología:

se responde concediendo que los actos de un atributo ò raçon no se atribuyen à otro. Pero se niega, que los atributos y raçones divinas no se distingan, sino solo con distincion de raçon raciocinante; porque se entiende de raçon raciocinada, ò cum fundamento in re, ò ex natura rei, ò virtualiter, concedemos ser assi. Y lo enseña Raymundo Lullio y es verdad que el entendimiento [humano] no puede quitar, ny poner cosa alguna realmente en la essencia de Dios. Pero le quitaria, si negasse, como haze el Repondiente, que el entendimiento divino produce, entendiendose Dios à si mismo, y la voluntad amando lo producido, y lo producido reciprocamente al produciente.

$\mathrm{Ni}$ hay Catholico alguno que niegue que ... todos los ... atributos y razones se identifiquen en la misma essencia; porque son la misma essencia divina ... Pero negamos que ... se distingan solo por nuestro entendimiento raciocinante. Y que las propiedades personales no se distingan realmente entre sy ... pero sy que haya en Dios distincion real entre las propiedades personales ...

Tras repetir que es falso que la bondad sea bonificativa de Dios, y la unidad unificativa de su esencia, etc., porque son el mismo Dios, insiste en que el Padre ama al Hijo y este a aquel produciéndose el Espíritu Santo, «Pero como las acciones son de los supuestos, se atribuye la omnipotencia al Padre, la Sabiduria el Hijo, y el 


\section{R E'P () N S E.}

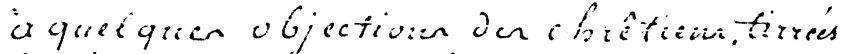
de divern passagon de l'Pcieture Saritite par len quellesil preten dent prouver le Mrystree de la. Finite den fersomen en Diece. par

\section{J)()N ISAC ()ROJ3IO) CASTRRO.}

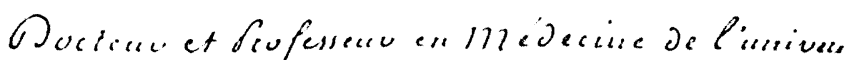
sité Je toufurse, et coreseill'co humuraire,de sa 101 ajestétion Chrêticume fouir XIV.

\section{() UIV Vire}

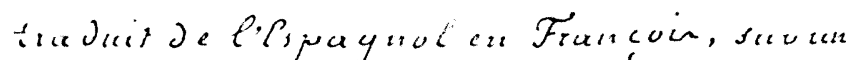

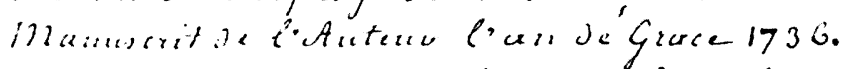
couritazit ell quate discuarn. Jaun'len

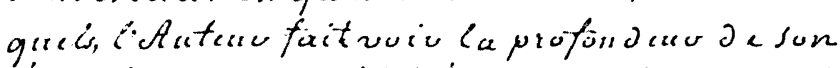
errodion. of la solidite de sone icrisomenent

\section{contre}

\section{I) ()N ALl'H()NSE JJE 'ZEl'E])}

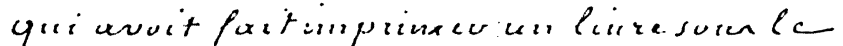
fitre, Je Ouctirine Je Raimono sulle, oil il enumit cummenté len frincipere

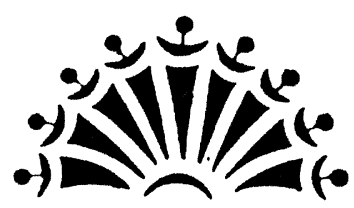

Patrimonio Nacional (reproducción permitida exclusivamente para Sefarad, F. Díaz Esteban) 
amor al Espiritu Sancto; aunque todos sean iguales en la omnipotencia, amor, y sabiduria».

El entendimiento y la voluntad en Dios (punto 16) son verdaderos, aunque no se da como en nosotros

por modo de potencias porque son acto purissimo y simplicissimo ... Pero se niega que no se distingan formalmente; y assi mismo sus actos; porque Dios no entiende por la voluntad, ni ama por el entendimiento ... estas acciones son substanciales y el mismo Dios, porque todo lo que hay en Dios es Dios. Y no apruebo que un tan gran Estudiante repita tantas veces una misma cosa, quando reprehende [reprende] a Raymundo Lullio de repetir muchas veces una misma cosa, no siendo assi.

Además de lo que cristianos e israelitas saben de Dios sólo por la fe,

negamos ... el que no sepamos .. mas de el, que los effectos, que produce ad extra: porque conocemos que de necessidad necessitante se deben dar las producciones divinas, ò que Dios no sera [no sería entonces] Dios ... Ny por esto queremos decir que penetramos la essencia de Dios, ni sus operaciones, como son en sy: porque ... nuestro entendimiento, seria mayor que Dios. Pero dice Raymundo Lullio, y prueba ser necessario el que haya Dios que sea uno, bueno, infinito, \&c. ... [que] es necessario tambien que no estè ocioso, y que produsga desde toda la eternidad: y que no puede producir en ella [más] que à Dios, que es su Hijo ... Por lo qual dice excelentissimamente el Arbol de Raymundo Lullio que si Dios no unificara a otro, habria en el minoridad.

Raymundo Lullio usò de exemplos, que los pudiessen entender todos, diferentes de los que acostumbran en las escuelas. Y el [ejemplo] de el Herrero y clavo es muy propio ... de la misma manera Dios no puede obrar sin unificar a otro.

Zepeda insiste (punto 17) en que la anterior comparación, si no totalmente adecuada, por la distancia entre lo finito y lo infinito, sí es

representativa à su modo de la necessaria produccion de la unidad: lo qual no se ha de entender (como quiere el Respondiente) respecto de Dios, como si estubiera en Dios en acto primero para haçer uno; y que Dios este en potencia ò acto signato para producirlo ... y menos que ... unifique otra Persona, que estaba en potencia para ser unificada. Porque todo esto es falso y chimerico, y los argumentos de Arrio: por quanto lo que dice Raymundo Lullio es lo que tantas veces se ha repetido, que la unidad es el 
mismo Dios ... que el inteligible y unificable ... siempre sera entendido y unificado ... Y respecto de nuestro tiempo à cuyas partes todas coexiste la eternidad.

De que se infiere la poca justicia con que el Respondiente condena los terminos y voces de Raymundo Lullio por significativas de obgetos chymericos y fingidos. Porque significan las razones verdaderas que realmente se hallan en Dios, sin las quales Dios no sera Dios: y creame vuestra M. Señor Lorenço, que el no assentir a ellas es delirio, y querer vivir ciego voluntariamente.

Se aborda (punto 18) la relación entre el objeto y la potencia en el nivel físico y en el metafísico:

Porque en lo increado el objeto no se presupone a la potencia, antes [bien] esta se presupone àl objeto, con una prioridad de origen solamente ... no de tiempo ni de naturaleza porque es forçoso concibamos primero Padre que Hijo. Casi como ... de todo lo creado ... pero su prioridad es de naturaleza ... primero el bonificativo que el bonificable ... en los entes de razon el obgeto se presupone a la potencia, y mas en la doctrina de Raymundo Lullio ... Por lo qual recognosco realmente y por la dificultad que objeta el Respondiente, que no leyò mi introductorio à fol. 92. ... Empero el Resp. ... supone que la Sabiduria es lo mismo en lo increado y en lo creado ... en lo creado es un habito de el entendimiento (como se dedujo en los primeros folios de mi introductorio). $\mathrm{Y}$ en lo increado es el mismo Dios ... Pero las luces de la Sabiduria no son para los entendimientos apartados de la verdad ... El entendimiento humano ... sin especies impresas no puede entender ... lo exterior ... si S. Thomas en algun lugar las niega, en la I parte se explica y las concede y juzga necessarias ... Y assi digo que si el tal Padre Minimo ha impresso el tratado que dice el Resp. negando absolutamente las especies impressas, y expressas hallara muchos que le respondan y abatan su delirio ... El Resp. se manifiesta en volver à negar en Dios la especie expressa ... esta es tan necesaria en Dios como su misma essencia: pues si se entiende à si mismo y à su fecundidad, es necessario que engendre àl Verbo; y ya havemos respondido à todo lo que puede decir en contrario; y probado como por la creatura, imagen y semejança de Dios, podemos rastrear algo de sus operaciones ad intra, y de sus divinas perfecciones.

\section{La objeción de Orobio (punto 19) para Zepeda}

no requiere Respuesta, por ser juguete y chiste. Porque si los Doctores Clasicos y S. Agustin se reducen ultimamente à que este sacrosancto misterio es de fée, lo mismo hace Raymundo 
Lullio: porque siempre pone la fée delante como guia y conductora del entendimiento; y jamas ha dicho (como finge el Resp.) que este articulo de fée ni otro alguno sea demonstrable por demonstracion a priori; sino solo el que se pueda probar por raçones naturales y necessarias. Y que se puede hacer es evidente ... Pero no se pueden demonstrar a priori; porque esta demonstracion causa el conocimiento de las cosas por sus causas, y este no se puede tener en las cosas de la fée.

Se insiste (punto 20) en la diferencia de Personas, aunque son todas la misma esencia

Y niego ... ser ...ficcion de nuestro entendimiento racicinante o chimericante; como he repetido tantas veces por haverme obligado a ello el Resp ... Confiesso [que la dificultad] es tan grande como el misterio. Pero que ha ella se han dado diversas soluciones, que se manifiestan en el Arbol Lulliano, siendo evidente, que el bonificador y bonificable ... se distingue de el bonificar ... aquel por el engendrar; y el bonificar ... por el amar ... Y todos los S. Doctores y los Clasicos que alega conspiran (como dice) la impossibilidad de el conocimiento de la differencia por los sentidos exteriores, como pretendia Arrio; pero no digeron, que no se podia tener mediante la fée el conocimiento, que se ha deducido.

Sobre el entendimiento y voluntad, considera (punto 21) respondido con lo anterior, y «pregunto a esse Cavallero, me diga en que parte Raymundo Lullio atribuye las mismas operaciones àl entendimiento que à la voluntad divina. Porque no es justo alegar con falsedad y acusar à un Autor de lo que no ha dicho».

Zepeda vuelve a repetir (punto 22) la necesidad del -avo, -able, - ar y que no pueden faltar en Dios, porque sería un defecto, y se queja de que

el Resp. no obstante su mucha philosophia està muy olvidado de las operaciones inmanentes e intrinsecas de los entes naturales: porque el calor, la quantidad, la blancura y demas accidentes lo son; y por esso necessitan de subgeto de inhesion por su misma naturaleza: pero no obstante tienen sus correlativos.

Otro reproche sobre las operaciones ad intra y ad extra: «el Resp. sale de la materia porque de las operaciones ad intra procede a las ad extra ... en la creacion de las creaturas, y ad extra concurre toda la Summa Trinidad. Pero en las ad intra solo el Padre y ambos al Espiritu Santo». 
Zepeda acepta (punto 23) el argumento de la unidad deducido por Orobio de Raimundo Lulio, pero considera falso el que forma por contraposición, pues

no dice negacion de otro uno que es su misma essencia y naturaleza ... Ny haçe gran fuerza el axioma $2=3,3$ iguales ... Porque el tal axioma se verifica absolutamente en lo creado ... no se verifica en lo divino ... Conque puede reconer V. M. Señor Lorenço y esse Cavallero, que el Arbol Lulliano enseña mas sutileças y verdades sin travesura, que las que alcança su ceguedad.

Se pregunta (punto 24) quién ha dicho que la bondad divina depende de otro para sus operaciones. Con sorna responde Zepeda a la pregunta «que hacia aquel entendimiento y voluntad divina antes de la creacion del mundo, que se effectuo havra cosa de 5613 años: estabase muy ociosito ò pensaba à caza en los bosques, que havia de crear para que se cortase leña en ellos».

En el punto 25 y final Zepeda se remite a todo lo que ha venido diciendo «Porque Dios produce desde toda la eternidad otro, que es su misma substancia». Defiende a los químicos atacados por Orobio y termina diciendo: «Pero no he respondido currente calamo, sino muy pensado ... retroceda del precipicio. A 28 de Julio 1663. Firmado D. Alonso de Zepeda».

\section{RÉPLICA SEGUNDA: TRADUCCIÓN FRANCESA}

De la segunda réplica de Orobio ha dado cuenta Yosef Kaplan (From Chistianity págs. 179-188), que ha contado 8 manuscritos (7 en Ámsterdam y 1 en París), ninguno de los cuales ha sido publicado. Como una secuela de esta polémica hay otro manuscrito «Sobre la Trinidad», claramente anticristiano y que, en opinión de Kaplan (pág. 188), también es obra de Orobio. Ni Kaplan, ni Simón Díaz, ni Harm den Boer ${ }^{5}$ conocen, al parecer, otro manuscrito existente en la Biblioteca del Palacio Real de Madrid con la segunda réplica de Orobio. Se trata de la traducción al francés hecha en 1736, según dice el traductor-copista, de un manuscrito en español del propio Orobio. Que este manuscrito fuera el autógrafo de Orobio o una de sus copias enumeradas por Kaplan habrán de dilucidarlo quienes tienen comodidad para consultarlos.

\footnotetext{
${ }^{5}$ La literatura sefardí de Amsterdam (Alcalá 1996).
} 
El manuscrito (papel, $18,2 \mathrm{~cm} . \times 11 \mathrm{~cm}$.) está encuadernado como libro; consta de 164 páginas y está repartido en cuatro Discours. No tiene colofón ni indicación del nombre del traductorcopista ni del lugar donde se ha hecho (¿en el mismo Ámsterdam?). En todo caso tiene en su francés de la época un cierto tufillo a hispanismos que se han infiltrado en la traducción, como si el traductor fuera español o judío hispano-portugués. La escritura, letra italiana menuda, tiene caracteres equívocos $(n, u, r, v, o$, $a, e, i)$ cuyo valor exacto a veces hay que deducir por lo que corresponde a la palabra de la frase francesa. Los acentos agudos y graves de la ortografía francesa faltan con frecuencia. La tinta es de color castaño claro. El libro no tiene notas de propietario ni otros detalles, no habiéndome sido posible, hasta ahora, el enterarme de la procedencia ni cómo el manuscrito llegó a la Real Biblioteca.

En el siglo XVIII Orobio de Castro gozó de prestigio en determinados círculos franceses. En Londres y en 1770 se publicó una especie de antología suya traducida al francés: Israel Vengé ou Exposition naturelle des Prophéties Hébrä̈ques que les Chretiens appliquent à Jesus, leur prétendu Messie. Par Isaac Orobio. Según Kaplan (From Christianity), se eligió en esta ocasión a Orobio por lo que tenía de anticristiano, pues sus editores eran escépticos.

Una finalidad opuesta es la de los editores franceses de otra obra suya, aunque su texto se dejó en el latín original, por lo que tenía de oposición a las ideas de J. Bredenburg y de Benito Espinoza: su Certamen philosophicum, que se imprimió como uno de los variados componentes de la polémica anti-espinoziana que forman el libro Refutation der Erreurs de Benoit de Spinosa. Par M. De Fenelon Archevêque de Cambray, par la P. Lami Benedictin \& par M. le Comte de Boullainvilliers. Avec la vie de Spinosa ecrite par M. Jean Colerus, Ministre de l'Eglise Lutherierienne de la Haye; augmenté de beaucoup de particularites tirés d'une Vie Manuscrite de ce Philosophe, faite par un de ses amis. Bruxelles, F. Foppens, MDCCXXXI. El Certamen de Orobio, impreso al final, ocupa las páginas 387-483, precedido de un «Monitum Editoris» en el que se dice que «nemo est inter Eruditos cui non fuerit cognita $\&$ perspecta Doctissimi inter hodiernos Amstelodamenses Hebraeos Ishak Orobio doctrina; paucit tamen in Belgio, at multo pauciores sunt in Gallia qui ejus scripta legerint», y lleva la fecha de 1731. 
Hay que recordar que Orobio murió en 1689. La portada de esta reedición lleva la fecha de 1703: Certamen Philosophicum Propugnantae Veritatis Divine ac Naturalis Adversus Joh, Bredenburg; Principia in fine annexa Ex quibus quod Religio rationi repugnat, demonstrare nititur Quo in Atheism Spinosae barathro inmersus jacet. Quod Religio nil rationi repugnans creddendum proponit, evidenter ostenditur Haec meditabutur Ishak Orobio Medicinae Doctor Amstelodamensis. Amstelaedami, Th. Ossaan, MDCCIII.

A este interés francés dieciochesco hay que añadir ahora el manuscrito de 1736. El título del manuscrito ${ }^{6}$ de la Real Biblioteca es:

RÉPONSE. / à quelques objections des chrêtiens tirrées / de divers passages de l'Ecriture Sainte par / les quelles il prétendent prouver la Mystere I de la Tinite des Personnes en Dieu. I par I DON ISAC OROBIO CASTRO. / Docteur et Professeur en Médicine de l'univer/sité de Toulouse, et conseiller honoraire de / sa Majesté très Chrêtienne Louis XIV. I ouvrage / traduit de l'Espagnol en François sur un / Manuscrit de l'Auteur l'an de Grace 1736. / consistant en quatre discours dans les / quels, l'Auteur / fait voir la profondeur de son / érudition et la solidité de son raisonnement / contre / DON ALPHONSE DE ZEPEDA / qui avait fait imprimer un livre sous le / titre, de Doctrine de Raimond Lull, où il / en avait commenté les Principes.

El manuscrito tiene pocos errores, aunque sorprende el que precisamente en la portada tenga tirrées, con una $r$ de más, y Tinite, que no creo que se deba a repugnancia a escribir Trinidad correctamente, pues en el cuerpo del manuscrito tiene Trinité sin equivocación.

Los textos los reproduzco tal cual están escritos, con la puntuación que llevan en el manuscrito original.

Lo mismo que Zepeda en la Propugnatio terminorum no daba el nombre de Orobio y le llamaba el «Respondiente», Orobio tampoco nombra a Zepeda y le llama siempre, en esta versión francesa, «le Commentateur».

Orobio deja aparte los argumentos filosóficos de Zepeda y trata solamente los versículos bíblicos que de manera ocasional emplea

\footnotetext{
${ }^{6}$ Real Biblioteca, II/1955 (olim 2-III-7, 1124241); encuadernación del siglo XVIII.
} 
Zepeda dentro de su extensa contrarréplica. Como en la primera réplica refiriéndose a Raimundo Lulio, Orobio se cura en salud diciendo que no va contra la religión cristiana, sino que la interpretación de Zepeda es errónea, para lo que aduce las traducciones de Arias Montano y Santes Pagnino, Padres de la Iglesia y teólogos cristianos. El estilo satírico y de superioridad de la primera Respuesta es ahora más académico, aunque no exento de ironía.

Quizás porque Zepeda le había replicado con autoridad de conocedor de la filosofía escolástica, Orobio no se atreve ahora a darle una contestación filosófica, sino que se va por el camino más fácil de combatir la siempre subjetiva interpretación de determinados versículos bíblicos, probando que la Vulgata, en la que se apoya Zepeda por no saber hebreo, no siempre es fiel al texto hebreo original.

La segunda réplica a Zepeda la divide Orobio en cuatro capítulos o Discursos, que llevan una indicación del contenido a modo de titulillo al principio de cada uno.

\subsection{Discours Premier Qui contient l'explication d'un passage tiré du Chapître dix-huit de la Génese}

Niega la posibilidad de que la «fecundidad» de Dios se deduzca de este versículo, y de que la argumentación aducida por Zepeda sea la correcta. Por otra parte, dice que se ha visto forzado a intervenir por las veces que Zepeda le ha pedido que le conteste si es capaz.

Pour prouver la fécondité dans l'Essence Divine, qui n'est outre chose que le Mystère de la Trinite; le Commentateur rapporte divers Textes de l'Écriture Sainte et il me prie avec instance de vouloir y repondre: il ne laisse pourtant pas chemin faisant, de pronuncer plusiers fois d'une maniere decisive, que je ne saurai pas le faire. Je me determine avec peine à me faire une occupation serieuse de traiter cette matiere; parce que ni dans mon petit Manuscrit, ni dans ces discours je n'ai pas pretendu disputer de religion; mais seulement combattre quelques raisons emploiées par le Commentateur; pour lui en faire sentir la faiblesse: cependant pour lui donner satisfaction, je lui dirai de quelle maniere nos Docteurs, et nombre de ceux de la religion, entendent ces passages que sont si vulgaires que je suis surpris 


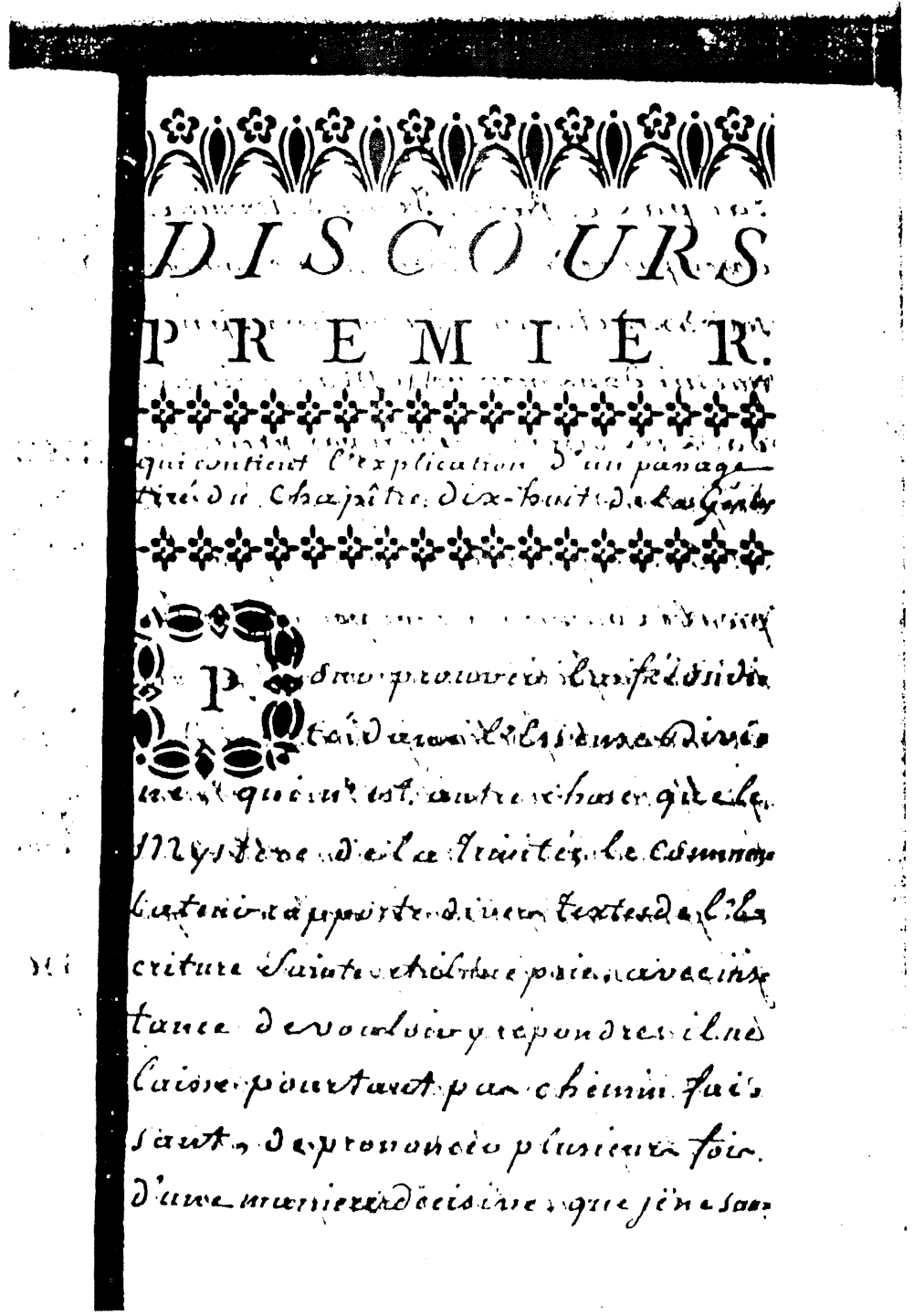

Patrimonio Nacional (reproducción permitida exclusivamente para Sefarad, F. Díaz Esteban) 
de ce que le Commentateur les a proposés a comme une doctrine ignore ou comme la botte secrete que ses études, et ses meditations luy avoïent apprises pour combatre la Religion des Juifs.

Le premier es tire de la Génese Chapitre dix huit, où le Texte Sacre dit: qu'Abraham vit trois anges et que courant à eux, il se prosterna devant eux ... Par où il semble qu'Abraham adora la Trinite, c'ést a dire, une Divinité en trois Personnes, Divinite qui semble lui avoir été réprésenté par les trois anges qu'il adora comme une qu'il $n$ y en avoit eu qu'un, A qu'il apella du nom de Dieu Adonay ... [págs. 2-4].

El que Abraham les hubiera adorado, o por mejor decir, honrado como uno solo no probaría ningún Misterio «non plus que de dire qu'ils veneient aun nombre de trois de la part d'un seule Dieu», además de que uno venía a anunciar el nacimiento de Isaac y los otros dos a destruir a Sodoma y Gomorra y a salvar a Lot. Abraham corrió a ejercer la hospitalidad a la que alude Pablo en la Epístola a los Hebreos 13,2. Y lo mismo opina San Agustín (Ciudad de Dios cap. 29). Opinan contrariamente Arrio e Hilario (según Atanasio, Sermo 4), pero si Abraham hubiera sabido que eran ángeles hubiera sido absurdo ofrecerles alimentos; lo conoció cuando ellos se lo dijeron.

Por otra parte, el Texto Sagrado no dice que Abraham les hubiera hablado en singular, sino solamente en plural, pues Adonay es en hebreo 'mis Señores'. Orobio no acude a los rabinos para confirmar lo que dice «mais seulement par l'autorité des plus célébres Docteurs de l'Eglise Crêtienne ... le cèlebre Arias Montanus, fameux interprête de toute la Bible, et du Nouveau Testament et dont l'interpretation a eu la approbation de toute l'Eglise Romaine, et il vera que dans ce passage il n'a pas traduit Monseigneur, mais Mes Seigneurs» (pág. 9). Pagnino y la Vulgata leen «mi Señor»

parce qu'ils veulent insinuer qu'Abraham parle à Dieu sans avoir aucun égard à la verité littérale du Texte Hébreu, mais seulement au sens que leur Eglise veut donner à ces passages. Pour rèmedier à cet inconvenient, on fit par ordre de Philippe Second la version interlinaire latine mot par mot qu'il fut executée par le grand Arias Montanus avec le conseil et l'assistence des plus savants personnages de l'Eglise Romaine ... dans ce passage Pagninus est indiqué en marge, pour fair voir que sa version ne s'accorde pas avec la verite litterale du Text [pág. 10].

No se usa Adonay en singular, aunque «c'est un idiotisme de la Langue Sainte, pour attribuer plus de grandeur à la chose 
signifiée» (pág. 11). Abraham dice Adonay, como si se hubiera dirigido a tres hombres y les hubiera llamado «mis Señores». Los Doctores que han explicado la Escritura así lo han interpretado, y no tenían menos interés en la Trinidad que Arias Montano. El que luego Abraham siga hablando y diga «si he hallado gracia en tus ojos», en singular, en vez de «vuestros» ojos,

ne fait aucune difficulté pour ceux qui sont versés dans la connoisence de la Langue Sainte, parceque c'est un stile qui lui est particulier de ne pas suivre toujours la concordance comme le Grecque \& la Latine ... il est très usité de prendre la Pluriel por le singulier, \& le singulier pour le pluriel [pág. 14].

Aduce, para informar al «Commentateur» Génesis 19, cuando Lot llama a los dos ángeles Adonay, que Arias Montano y Pagnino traducen 'señores', pero la Vulgata 'señor'; así, por la misma razón «on pourrait en déduire un mystére de Dualité» (págs. 16-17), lo que sería contrario a la doctrina de la Iglesia.

6.2. Discours Second. Ou l'on examine au argument de convenance que le Commentateur tire du Chapitre ving huit et trante cinq de la Genése, por prouver la trinité on examine aussi un verset du Psaume deux et un autre du Prophéte Michée

Sigue Orobio corrigiendo las interpretaciones de Zepeda, como es el caso de Génesis 28. El «Commentateur» arguye que cuando Jacob levanta un altar para sacrificar, solamente repite tres veces que «esta era la casa de Dios», tanto en el cap. 28 como en el 35, «d'on conclut que par ces trois fois il a voulu denoter la trinité attendu qu'on ne peut pas donner d'autre raison» (pág. 21). Pero se equivoca, porque Jacob ni le ha sacrificado ni le ha levantado un altar, «il a dit seulement en Bethel que cet endroit etait la maiestá asentado Jerusalén, como se puede ver por el Cardenal Cayetano y Nicolás de Lyra. El que el Abulensis no piense así, no hayque tenerlo en cuenta, pues lo confirman numerosos Doctores son de Dieu ...» (pág. 21). Betel es la montaña de Moria, donde está asentado Jerusalén, como se puede ver por el Cardenal Cayetano y Nicolás de Lyra. El que el Abulensis no piense así, no hay que tenerlo en cuenta, pues lo confirman numerosos Doctores graves y Pineda en su Monarchia Ecclesiastica, es la opinión común: «cela est si universellement reçu parmi les Docteurs Chrétiens aussi bien que parmi les Hebreux» (pág. 24). 


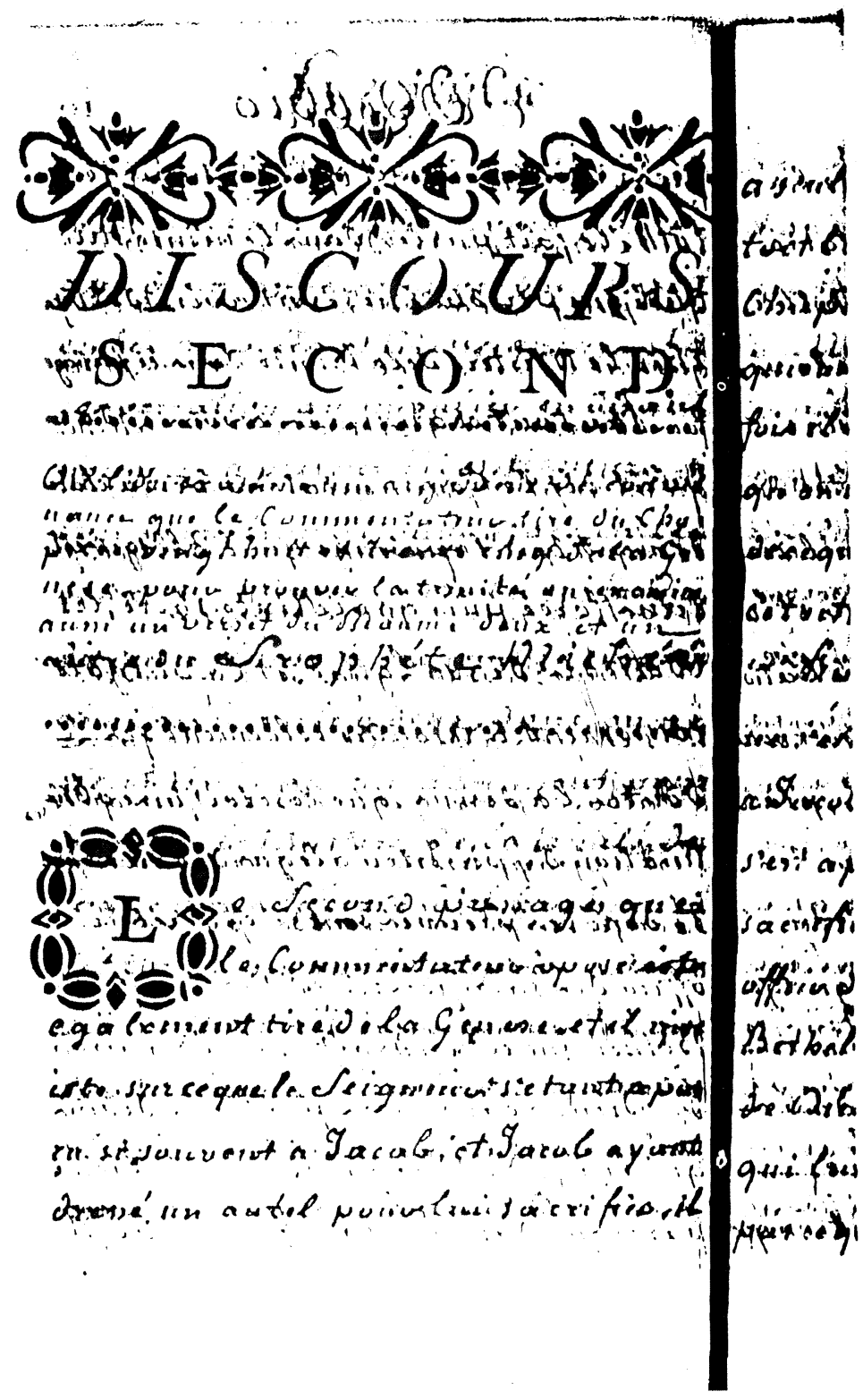

Patrimonio Nacional (reproducción permitida exclusivamente para Sefarad, F. Díaz Esteban) 
El número de veces que ocurre algo no tiene significado:

On ne peut inferer aucun mystére de ce que la même chose est arrivé trois fois a Jacob ... dans l'Ecriture Sainte une infinité de choses qui sont arrivées deux, quatre et cinq fois qui servient aussi propres à nous indiquer de grands mystéres que celles que ne sont arrivées que trois fois [pág. 25].

Orobio expone a continuación su credo judío basado en el Pentateuco y en la creencia unánime del pueblo judío a lo largo del tiempo; la frase es una exposición magistral de la "perfidia» (es decir, de la permanencia en la fe, que es lo que significa perfidia en latín), mantenida por los antepasados:

ils ne puevent rien croire a cet égard que ce que cette divinité même a dit de soi clairement et sans ambiguité dans le registre Sacré qui contient ses paroles, les Juif ne croïent pas non plus de voir entendre les ecritures Divines selon l'intelligence, ou selon la foi que les nations leur proposent mais seulement de la manière ont recues et entendues leurs Peres, qui étaient des Prophetes, des Saints et des Docteurs, et de la manière que les croient et les entendent toute l'assemblée de le Peuple d'Israel [pág. 27].

El salmo 2, donde se dice «tú eres mi hijo, hoy te he engendrado», es utilizado por el «Commentateur» para demostrar que Jesús es Hijo de Dios. Orobio arguye que son innumerables los pasajes donde se llama al pueblo de Israel «mi hijo», y que esta filiación se entiende tanto de uno solo como de todo el colectivo. Aplicarlo a Jesús como el Hijo de Dios, con la importancia que tendría la Encarnación, hubiera exigido una formulación más explícita:

fins dif L'Israelite ne puet pas croire qu'un Mystere si necessarie à la salut des hommes, n'aïe été marqué par la providence de Dieu que dans un petit mot du Psalmiste ou de quelque autre Prophéte dont cette même providence aïe remis l'interpretation a la faible intelligence des hommes, ni qu'elle aye laisse tant d'ambiguité dans le sens des paroles ... car il y aurait de la bétise de se persuader que les Juifs par obstination veillent vivre et mourir dans l'erreur: puis que Dieu a daigné reveler a ce même peuple tout ce qui leur était necessaire de savoir de sa divine Essence, et cela dans les livres qui contiennent la Loi ... et don't l'autorité ne dépend en aucune sorte de Psaumes ni des Prophétes qui ont écrit pleusiers siecles après pour des ferents ... sans faire aucune mention de ce mystéres ... jusqu'a a ce que les gentils en aïent donne explication aux juif, et que ceux cy s'en 
soient raporter a la explication que les gentils en ont donnée ... mais on en trouve plusieurs qui leur deffendent de suivre les sentiments des Gentils ... nos Péres n'on jamais connu Dieu les fils, ni Dieu le Saint Esprit; et c'est verité confirmée pour toute l'Eglise Chrêtienne que ce mystére a été premierement revélé dans l'Evangile» [págs. 34-38].

A lo que dice el «Commentateur» de que aplicar esta expresión a David sería como llamarle presuntuoso que pretende ser hijo de Dios, Orobio replica que si no nos avergozamos de llamar a Dios «notre Pere nous pouvons avec confiance nous dire ses enfants» (pág. 43). La doctrina cristiana sobre la idea de filiación en este salmo es de un género diferente, «c'est un Dogme de sa foi sur le quel il ne m'est pas permis de disputer; c'est pourquoi je me suis contenté de rapporter dans ce discours les motifs qui determine les Juifs a ne pas recevoir ce Dogma» (pág. 43).

Otro versículo bíblico aducido por Zepeda está en el Profeta Miqueas (Miq 5,2), cuando dice «Belén Efrata, de tí me saldrá quien ha de ser dominador en Israel, y cuyos origenes vienen de antaño, desde los dias antiguos». Zepeda tiene nacerá en lugar de saldrá y desde el comienzo, desde la eternidad. La culpa no está en Zepeda, sino en querer seguir ideológicamente a la Vulgata,

puisqu'il y a beaucoup de difference entre sortir, descendre, venir, de Madrid ou naitre dans Madrid, et être natif de cette ville, ainsi ce verset ne dit pas que ce Dominateur naîtra en Bethlem, mais qu'il en sortira ou qu'il en sera originaire; et c'est ainsi que l'ont traduit la Vulgate et tous les Docteurs [pág. 45].

Por otra parte, no hay salida, sino salidas, en plural, como traducen Arias Montano y Pagnino. El verdadero sentido del versículo es que el Mesías deberá descender de David, que era nativo de Belén-Efrata. En cuanto al término hebreo olam, no significa 'eternidad' más que cuando se relaciona con Dios, pero con las cosas creadas «elle signifie ou toute la durée d'une chose, ou un longtemps» (pág. 50), como ocurre en Isaias 52,63, Amós 9 y último de Miqueas. El «Commentateur» no prueba la generación de personas divinas ni que el Mesías haya ya venido, y aceptado que debe salir de Belén «ce qui ne se peut plus a présent attendu que cette ville est deja detruite» (pág. 56). 


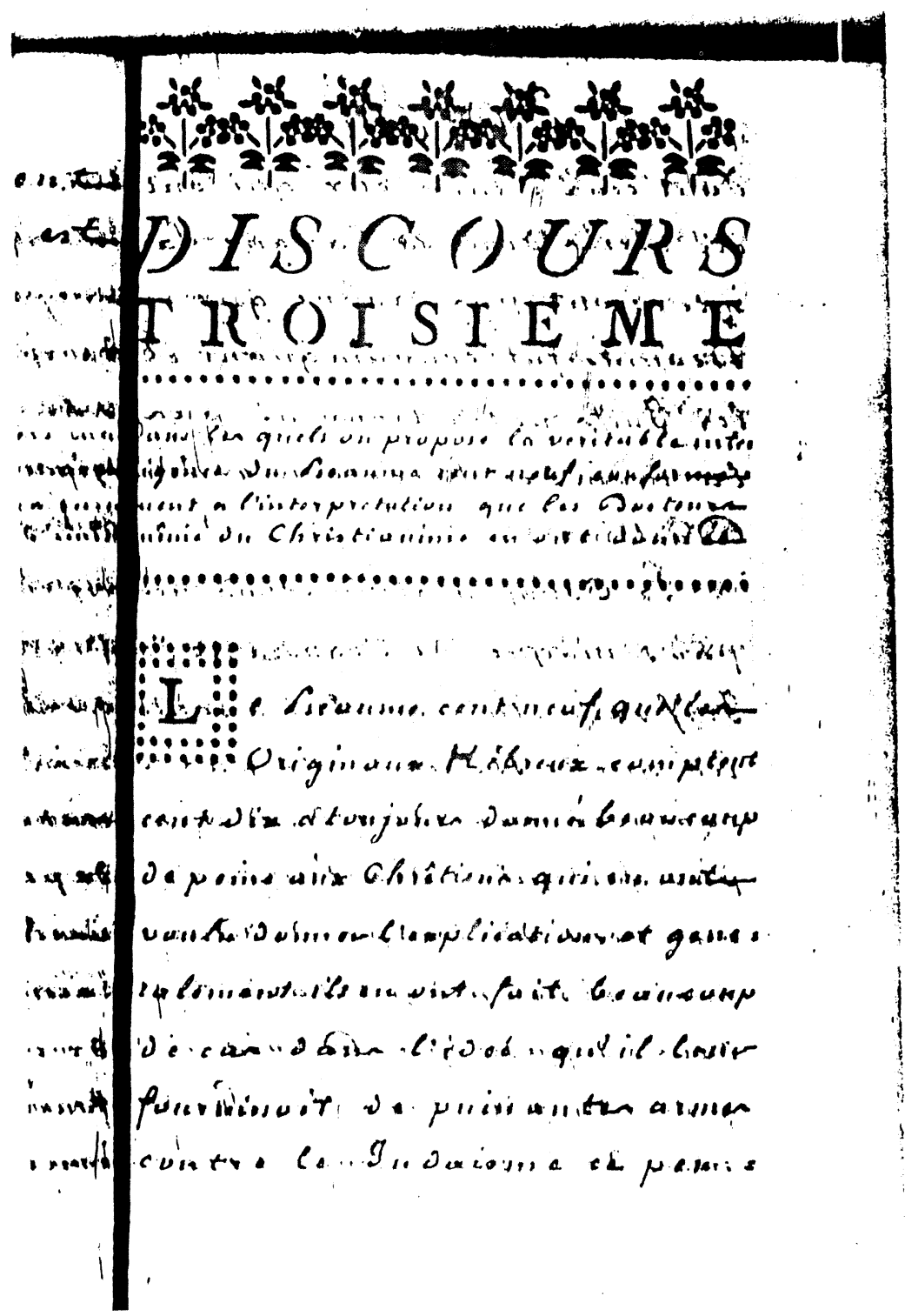

Patrimonio Nacional (reproducción permitida exclusivamente para Sefarad, F. Díaz Esteban) 
6.3. Discours Troisieme. Dans les quals on propose la veritable inteligence du Psaume cent neuf, conformement a l'interpretation que les Docteurs même du Christianisme en ont donné

Sigue Orobio aduciendo Autoridades cristianas para refutar las interpretaciones de versículos propuestas por Zepeda. Hay que recordar que el salmo 109 en el texto hebreo es el 110; ha sido usado por los cristianos contra el judaísmo, pero los que están duchos en la Lengua Santa «n'ont pas trouvé que ce Psaume fut convainquant et les Juifs ne lui trovent pas le moindre force contre leur Doctrine» (pág. 58).

Reprocha Orobio el que Zepeda se haya burlado de un judío sin estudios, como era el caso de Lorenzo Escudero, por sostener que este salmo no era de David, sino de uno de los profetas de su tiempo, cuando, como es sabido, no todos los salmos fueron escritos por David y en algunos casos llevan el nombre de sus autores. En el caso del salmo 109 se puede dudar, porque su titulación es ambigua: le-David puede significar 'de', 'para', 'por' David. Los judíos leen «para David», «pour croire qu'il est du nombre de ceux qui ont été composes par divers Prophétes du temps de David ... par inspiration de l'Esprit prophetique» (págs. 63-64). Como el salmo tiene Yahveh, Orobio aclara que es el tetragrammaton de los griegos, y como también tiene Adonay 'mi señor', que se puede aplicar a un hombre, algunos han traducido impropiamente «le Seigneur a dit a mon Seigneur supposant faussement de l'égalité entre la personne que parle, et celle à qui il adresse la parole mais le Texte Hébreu ne le permet pas» (pág. 65). El sentido es que a David se le pide que no salga más al frente de sus tropas y que se quede a la diestra del Señor, no porque Dios tenga brazos, sino espiritualmente, que se quede tranquilo protegido por Dios: «la droite du Seigneur selon la stile de l'Ecriture Sainte nous signifie son divin pouvoir, sa force et sa protection» (págs. 70-71), interpretación a la que Orobio dedica numerosos ejemplos.

Otro punto difícil es «del seno, de la la aurora» que

Arias Montanus traduit de la vulva ou Matrice de l'aurore ... Santes Pagninus lit du ventre de l'aurore ... mais le Commentateur est si consommé dans la lecture des écritures Saintes et de l'explication qu'en ont donnée ses Docteurs ... qu'il avance hardiment que les Hébreux avoient en ce endroit enlevé un verset 
entiere de l'oracle Sacré; sans doute parce qu'il n'a pas trouvé je t'ai engendré du ventre avant l'etoile du matin ... ni Saint Jerome, ni Saint Augustin, ni aucun outre Docteur célébre de l'Eglise Chrêtienne n'a ose proferer une calamite semblable ... Tous ces Docteurs conviennent donc, que les Juifs son les trésoriers et les dépositaires de la parole Divine dans sa pureté; et que c'est à leurs originaux Hébraïques qu'on doit avoir recurs pour decider en toute occurrence les doutes qui se present touchant la verité litterale ... il faut être bien stupide pour penser que tous les Juifs de l'universe ont conspiré ensemble pour effacer un verset, ou même une seule parole du Texte Sacré ... non pas même dans les Passages que l'Eglise Chrêtienne leur opose et qu'elle regarde comme leur plus favorables à sa doctrine [págs. 81-84].

Orobio se muestra desdeñoso con los no judíos que quieren impugnar la Biblia Hebrea, pues no es en las disputas ni en las sutilezas de las interpretaciones en lo que los judíos deseen perder el tiempo, porque saben que es la Ley lo que sostiene a los judíos «parce que Dieu ne nous a pas ordonné de disputer avec les Gentils touchant la Loi, mais seulement de croire un seul Dieu, et d'observer la Loi» (pág. 88).

$\mathrm{El}$ «Commentateur», dice Orobio, ha seguido a la Vulgata, cuyo autor en varios pasajes no ha seguido al original, sino que los ha traducido «selon le quel son Eglise les entend et qu'il s'est accommodé à la Phrase Latine autant qu'il l'est possible» (pág. 91), y da varios ejemplos de lo que en su opinión han sido errores intencionados de San Jerónimo, contraponiendo siempre la traducción de Arias Montano o de otros cristianos. Y en el salmo en cuestión (el 109) la forma en que lo cita Zepeda siguiendo a la Vulgata no está en el texto hebreo, de modo que se le podría inculpar de la misma calumnia que Zepeda imputa a los judíos de cambiar el texto, aunque de lo que habría que culparle es de meterse a lo que no sabe. La traducción «antes de la estrella de la mañana» no es lícita, porque solamente hay «del vientre de la aurora», y tampoco se puede decir «antes de la aurora yo te he engendrado», «cela n'est permis qu'a des moines qui se servent dans leurs Sermons de ces passages alterés, et sans s'atacher avec exactitude à l'interpretation littérale du Text Sacré se content de lui donner un sens mistique ou allegorique qui les conduit au but de leurs predications» (pág. 108). 
Insiste después en las peculiaridades de la lengua hebrea y en las dificultades de reproducir su estilo poético, como ha dicho el sabio Arias Montano en el prefacio de su versión de la Biblia. Lo mismo dijo San Jerónimo. Si el «Commentateur» tuviera buena fe, se convencería de que no ha visto una traducción fiel.

Zepeda yerra, según Orobio, al traducir el versículo 4: «el Señor ha jurado, y no se arrepentirá. Tú eres sacerdote para siempre a la manera de Melquisedec», pues no siempre kohén 'sacerdote', que significa 'sacrificador', tiene el mismo signficado: en ocasiones es «príncipe, presidente, Ministro de Dios o del Estado». Igualmente en 2 Samuel 8, último versículo, el plural kohanim 'sacerdotes' hay que interpretarlo como 'ministros', y no que «todos los hijos de David serán sacerdotes», y tampoco se dice en ningún lugar qué clase de sacrificador era Melquisedec, de modo que kohén aquí hay que interpretarlo por 'ministro de Dios'. La traducción, según Orobio, del salmo 109,2 tiene que ajustarse a que

Dans ce verset le prophéte pour inspirer à David la retraite et la tranquilité lui dit: le Seigneur a juré et il ne se repentira pas ... qui toi David seras toujours, s'est a dire, durant tout le cours de ta vie son Ministre, et que tu regnaras ... Que si on prétend, comme Saint Paul veut insinuer que Melchisedek soit un nom propre dans ce passage ... il faudra entendre tu seras un Prince, ou tu seras mon Ministre, a toujours comme Melchi Sedek [págs. 123-126].

En todo caso, siempre las explicaciones pueden ser más amplias que las literales

parce que les Psaumes, aussi bien que tous les Textes Prophétiques sont susceptibles de plusiers explications qui sont toutes approvées de nos Docteurs pourvu qu'elles ne soient contraires ni à la verité litterale du Texte Sacré, ni a l'observation de la Loi de Moise. L'Eglise Crêtienne avec l'Apôtre donne un autre sens a ce Psaume, et je ne veux point combattre son explication, quoique ma religion ne me permettre pas d'y adhérer. Chacun trouve plus de conviction dans ses raisons que dans celles des autres et chacun est persuadé qu'il doit abonder en son seris selon le conseil de même Apôtre [pág. 138].

No se debe pasar por alto la declaración de libertad de interpretación que hace Orobio, aunque para un judío queda limitada por la necesaria aprobación de los rabinos basados en que respeta la norma judía; Orobio aquí refleja el mismo espíritu que Zepeda cuando este dice que se somete a la autoridad de la Iglesia. 


\subsection{Discours Quatrieme Où l'on donne l'explication d'un passage tire du Livre des Provers et d'un autre du Prophéte Isaie, selon le sens qui leur ont donné les interpretres Chrêstiens}

Esta última parte comienza con un intento de desprestigio a Zepeda, que sólo busca los pasajes que cree favorables:

et sans nous offrir rien de nouveau ou d'ignoré, il ne nous présent que des choses fort connues, il a trové dans le Chapitre huit le Proverbe vingt cinq [Prov 8,25] et sans l'avoir examiné il le rend <>nable par la manière dont il le raporte: car c'est ansi qu'il le lit d'après $\mathrm{M}<>$ lade son Villages: avant toutes les collines j'enfanta, et le Commentateur ajoute à cette Phrase: dit le seigneur un ne tonberait pas dans une $<>$ si grossiere si on $\mathrm{f}<>$ it attention que la Doctrine Chrêtienne enseigne a croir et a soutenir que Dieu a engendré, A que $1<>1$, est la production du Pure éternel, mais qu'elle n'explique pas cette Generation par le terme d'enfanter, et que ce stile lui est inconnu: cependant si le Commentateur a trouve cette expressions quelque part qu'il s'en serve, il n'importa pas: ce qu'il y a de plus important, c'est donc par falsifier lers Textes des Saints Livres, et si la Vulgate a voulu s'ecarter de la lettre pour s'accommoder au sens de son Eglise on doit la mettre a l'ecart, et ne chercher pour la conviction des Juifs que de passages cité selon la verité litterale parce qu'autrement on perd son temps en lui faisant des objections qui ne son d'aucune force contre lui [págs. 141-142].

... le Texte ne dit pas, avant les collines j'enfantois, dit le Seigneur, puis qu'il n'y a dans le Text ni le Seigneur, ni aucune diction equivalent, dans tout ce Chapitre: on introudit la sagesse adressant la parole aux hommes pour les persueder qu'ils doivent la chercher ... soit que l'Auteur entende la sagesse Divine, soit qu'il veuille parler de la sagesse crée ... dans la version d'Arias Montanus, dans celle de Pagninus et dans toutes versions que j'ai lu soit latine, flammade ou Espagnole ou francaise se lit en cette sorte: avant que les Montagnes <> ont été planté à l'aspect des collines j'ai été formée c'est ansi que lit Montanus, et Pagninus; avant que les Montagnes eussent été placées devant les collines[, i] quel raport a cette phrase avec celle cy: avant toutes les collines j'enfantais dit le Seigneur? il y a dans ce versét aucune parole qui puisse signifier engendrer ni enfanter il y a seulement que notre Seigneur a tout Crée par sa Divine Sagesse et qu'étent la directrice de tout l'ouvrage de la crátion il a falu qu'elle précedat toutes les choses Crées [págs. 143-145]. 


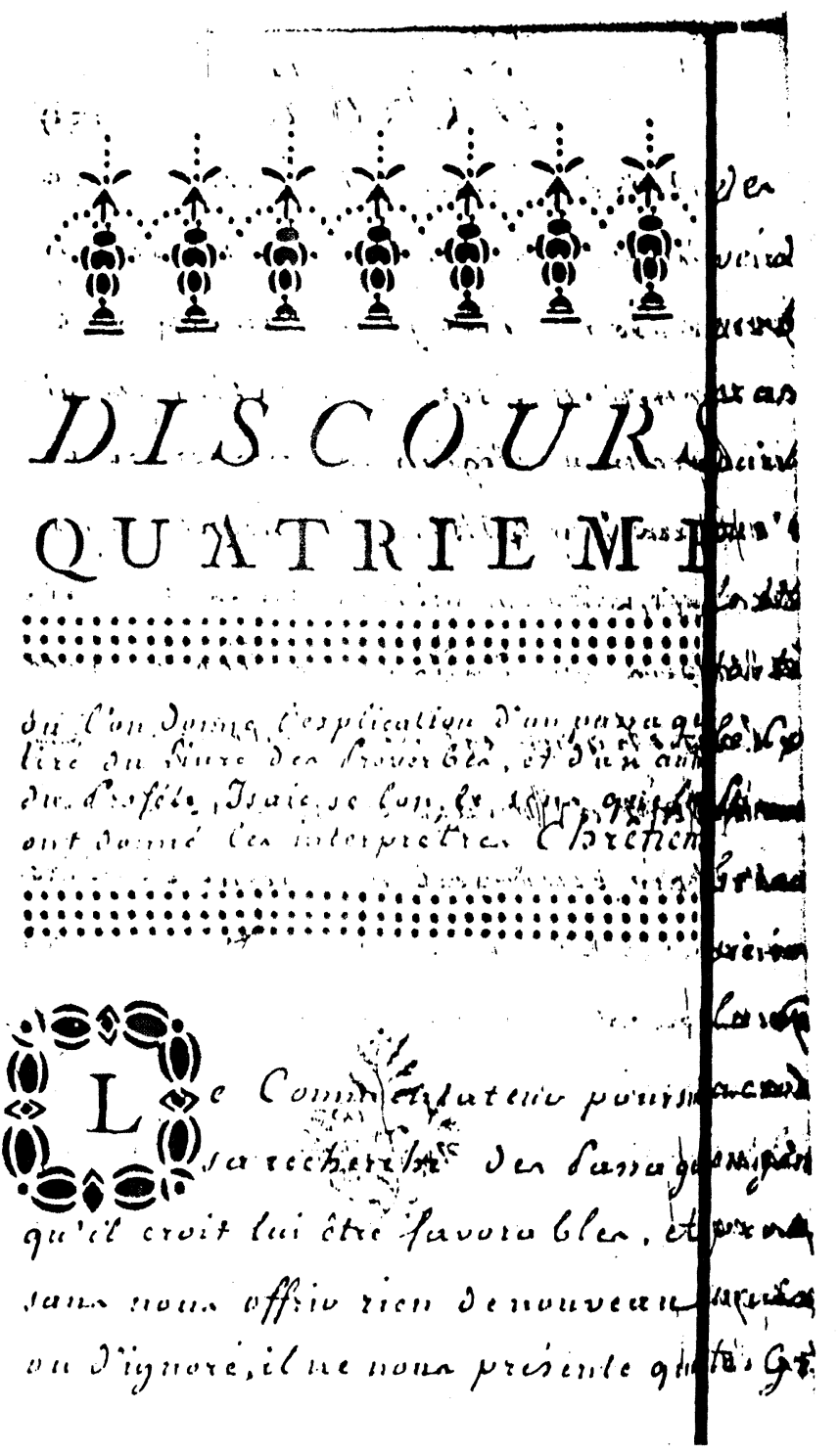

Patrimonio Nacional (reproducción permitida exclusivamente para Sefarad, F. Díaz Esteban 
En el capítulo 65, 66 según Orobio, Zepeda sitúa la frase «¿es que yo no pariré, yo que hago parir a los otros? ha dicho el Señor de los Ejércitos, ¿o sería yo estéril si yo doy a los otros la generación?». Pero la traducción de Arias Montano dice «¿es que abriría yo las matrices y no las haría parir?», que es literal del hebreo [Cantera, Is 66,9: «¿es que iba yo a abrir el seno materno, mas no a hacer parir? dice Yahveh»]; la segunda parte del versículo es «¿o habría yo, el que hace parir, de cerrarlo? afirma tu Dios». Ese es el texto «dans tout sa pureté et selon la traduction des plus fameux interpretes de l'Eglise des Chêtiens ... non pas de la manière que le cite, et la raporte le Commentateur ... on ne peut tirer aucune preuve, non pas même le moindre induction pour etablir que Dieu engendre» (págs. 150-151). La forma milagrosa como hace parir a Sión sus hijos sirve a Orobio para decir

le commentateur puet conclure deux choses la premiere que les serviters a qui cette regéneration est promise, doivent nécesairement être des Juifs, et qu'il ne peuvent pas être des autres nations, Mores ni Chrêtiens puisqu'inmédiatement aprés suit un autre Chaptire qui invite ces serviteurs de Dieu a jouir ... et qu'annonce ... le chatiment ceux qui mangent la chair de Cochon ... Les Docteurs Chrêtiens donnent a ce texte un autre explication, mais je rapporte ici l'éxplication que les Hébreux lui donnet [págs. 158-159].

La parte final, en que Dios reúne a sus servidores en la Jerusalén celeste, no cabe interpretarla como prueba de la generación de personas de la Trinidad como hace Zepeda, pues los doctores cristianos bien la interpretan como de la Iglesia militante reunida en los cielos con la Iglesia Triunfante, bien según la interpretación literal de los Israelitas. El «Commentateur» se molesta en convencer de buena fe citando la Vulgata en pasajes que los doctores cristianos interpretan de otra forma porque han seguido el texto hebreo,

le Commentateur doit me savoir bon gré de ce que dans mes résponses je n'ay voulu me servir que de l'autorité de ses Docteurs et de ses interpretes mêmes: parce que ne sachant pas la langue Hébraïque, il se pourroit toujours persuader que je le trompe, au bien qu'a présent il voit bien que je le détrompe, et que je lui dessille les yeux, a moins qu'il ne suspecte ses interpretes même d'être des falsificateurs ce que ne saurois croire con- 
noissant sa candeur et son erudition. Je lui proteste aussi que si j'ai répondu aux passages qu'il a proposé, ce n'a été que pour le satisfaire, et pour défendre l'honneur qu'il me fait de m'en prier, et nullement dans la vue de combattre le sens et l'inteligence que leurs donne l'Eglise Crêtienne. Finis [págs. 163-164].

Como en toda esta polémica, las formas amables, aunque llenas de ironía, suavizan las acusaciones mutuas de ignorancia: «Caballero», «Vuestra Merced», «Señor», «Filósofo», «Erudito», son los tratamientos de cortesía que se dirigen mutuamente; todos se reconocen dignos del combate intelectual, aunque se acusen de no saber interpretar correctamente o de no conocer el asunto de que tratan. Así como Zepeda no oculta su antipatía por el judaísmo, Orobio, por el contrario, es muy cuidadoso de no suscitar la cólera de los cristianos, pero al mismo tiempo sabe exponer y defender claramente la postura judía.

No sabemos si esta segunda réplica de Orobio llegó alguna vez a conocimiento de Alonso de Zepeda, aunque de haber sido así es raro que no escribiera a su vez una segunda contrarréplica, como hizo en el caso del cometa de 1680 con el Abad Juan Brabo de Sobre-Monte.

\section{RESUMEN}

En la polémica sobre la Trinidad se presentan textos de R. Lulio, Orobio de Castro y Alonso de Zepeda, y se da cuenta de un manuscrito de la Biblioteca de Palacio de Madrid.

\section{SUMMARY}

In the Trinity polemics selected texts are brought in from R. Lullius, Orobio de Castro and Alonso de Zepeda, and an account is given of a Manuscript in the Royal Library of Madrid. 